\title{
O MERCADO DE AMÊNDOAS DE Dipteryx odorada (CUMARU) NO ESTADO DO PARÁ
}

\author{
Tadeu Melo da Silva ${ }^{1}$, Fernando Cristovam da Silva Jardim², \\ Murilo da Serra Silva ${ }^{3}$, Patrícia Shanley ${ }^{4}$ \\ ${ }^{1}$ Eng. Agrônomo, M.Sc., CIFOR/EMBRAPA, Belém, PA, Brasil - tadeu.melo12@gmail.com \\ ${ }^{2}$ Eng. Florestal, Dr., Instituto de Ciências Agrárias, UFRA, Belém, PA, Brasil - fernando.jardim@ ufra.edu.br \\ ${ }^{3}$ Eng. Agrônomo, Mestrando em Agroecossistema, UFSC, CIFOR/EMBRAPA, Belém, PA, Brasil - mserra@cgair.org \\ ${ }^{4}$ Bióloga, Ph.D, CIFOR/EMBRAPA, Belém, PA, Brasil - pshanley@ cgair.org \\ Recebido para publicação: 19/08/2008 - Aceito para publicação: 19/02/2010
}

\begin{abstract}
Resumo
O presente artigo analisou o mercado de amêndoas de semente de cumaru (Dipteryx odorada (Aubl.) Willd.) no estado do Pará na safra de 2005. As informações secundárias foram obtidas através do Instituto Brasileiro de Geografia e Estatística IBGE e do sistema de informação Aliceweb, do Ministério do Desenvolvimento, Indústria e Comércio Exterior. As informações primárias da cadeia foram obtidas através de entrevistas com os agentes envolvidos na comercialização. Os resultados mostram que atualmente os principais países importadores são o Japão, França, Alemanha e China. Aproximadamente 2.700 famílias estão envolvidas no extrativismo de cumaru em todo os estado. As Margens Brutas foram, respectivamente, 20,0 e 15,0\% (paras os dois grupos de atravessadores), 33,3 e $46,7 \%$. Já a Markup foi de 75,0\% para os atravessadores, $166,7 \%$ para as empresas exportadoras do interior e $233,3 \%$ para as empresas atacadistas em Belém. No total o Markup foi de 500,0\%. O preço do quilo da amêndoa variou de $\mathrm{R} \$ 3,00$ para os extrativistas até $\mathrm{R} \$ 18,00$ para as empresas atacadistas. Também foi possível averiguar que os responsáveis pelo maior acréscimo de preço no produto são as empresas exportadoras, o que gera ganhos desproporcionais ao longo da cadeia. Palavras-chave: Cadeia produtiva; cumaru; extrativismo.
\end{abstract}

\begin{abstract}
The market of cumaru nuts (Dipteryx odorata) in the State of Pará, Brazil. The study aimed to present the results of a market study of cumaru nuts in the State of Pará, for the 2005 harvest. The data used in the research were obtained at the Brazilian Institute of Geography and Statistics (IBGE) and the exportation information system of the Ministry of Developing, Industry and Foreign Commerce (Aliceweb). The gross profit was $\mathrm{R} \$ 3.00, \mathrm{R} \$ 2.25$, and $\mathrm{R} \$ 7.00 / \mathrm{kg}$. But the markup was $75.0 \%$ for the intermediary, $166.7 \%$ for the interior wholesale companies, and $233.3 \%$ for the wholesale companies from Belém, the State capital. The total markup from the beginning to the end of the market chain was approximately $500 \%$. The price of the nut ranged from $\mathrm{R} \$ 3.00$ for the collectors to $\mathrm{R} \$ 18.00 / \mathrm{kg}$ for the wholesale companies. It was observed that the major additions to the product price were imposed by the exporting companies, which generate unequal gains within the chain. There are approximately 2.700 families involved in cumaru nuts collection that are exported mainly to Japan, France, Germany and China.
\end{abstract}

Keywords: Suplly chain; cumaru; extractvism.

\section{INTRODUÇÃO}

Os recursos florestais são importantes componentes da economia de milhares de pessoas ao redor do mundo. Os impostos, empregos e renda gerados pelo setor movimentam bilhões a cada ano. No Brasil, em 2006, foram gerados aproximadamente $\mathrm{R} \$ 10,9$ bilhões. Destes, $\mathrm{R} \$ 7,2$ bilhões $(66 \%)$ são provenientes da silvicultura, e o extrativismo vegetal responde por $\mathrm{R} \$ 3,7$ bilhões $(34 \%)$. Desse valor, $\mathrm{R} \$ 3,2$ bilhões são referentes à produção de madeira e carvão, e R \$ 539,2 milhões são gerados a partir da comercialização de produtos florestais não-madeireiros (PFNM) (IBGE, 2006). Ao contrário da extração 
comercial de madeira, os PFNM são de grande importância para as populações pobres, principalmente nos trópicos (SHANLEY, PIERCE, LAIRD, 2006; SANTOS, 2003).

De acordo com a Organização das Nações Unidas para Agricultura e Alimentação (FAO) (2002), os PFNM são definidos como "bens de origem biológica, diferentes da madeira, derivados dos bosques ou de outras áreas florestais e de árvores fora dos bosques". A comercialização desses produtos tem sido apontada como um aporte à economia de comunidades em situação de vulnerabilidade. Amêndoas, látex, resinas, animais silvestres e outros materiais fazem parte das opções para populações rurais e urbanas. A utilização desses produtos possibilita a geração de trabalho e renda, favorece o uso múltiplo dos recursos florestais e permite a valorização da cultura e o aproveitamento de espécies locais (MARSHAL, 2006; BALZON, 2004).

Porém muitas espécies que fornecem PFNM não foram devidamente estudadas, carecendo de informações sobre seu valor, quantidades produzidas, processos de produção (manejo e conservação), comercialização e industrialização de seus produtos. Além disso, a sazonalidade e a variação em sua produção geram uma lacuna de dados, que dificulta a conservação e o desenvolvimento de seus mercados (ZAMORA, 2001). Os PFNM representam um dos grupos mais complexos do ponto de vista da comercialização, devido ao seu número, versatilidade e variedade de aplicações. O mercado desses produtos vai desde feiras e estabelecimentos locais até mercados altamente especializados. Essa variabilidade impõe grande dificuldade na análise dessas cadeias produtivas e na identificação dos agentes que influenciam nos fluxos e na distribuição da renda dentro do mercado.

Muitas pesquisas evidenciaram limitações estruturais na cadeia de PFNM (RICKER; DAILY, 1998; HOMMA, 2004). Elas mostram a fragilidade de um sistema baseado na coleta de produtos disponíveis na natureza sem o emprego de tecnologias que otimizem seus resultados. Outros autores salientam as limitações da utilização dos PFNM como opção econômica para os trópicos (MARSHALL, NEWTON, SCHRECKENBERG, 2003; HOMMA, 2000; AMIM, 1997). Esses estudos mostram a característica cíclica dos mercados desses produtos e o iminente colapso da economia extrativista, devido a esses ciclos. Segundo esses autores, a almejada sustentabilidade econômica dificilmente será alcançada através do extrativismo, devido à baixa produtividade do sistema.

Por outro lado, vários pesquisadores mostram os benefícios estratégicos dos PFNM, tanto para a economia quanto para a conservação dos recursos florestais (NOGUEIRA, 2006; SHANLEY; MEDINA, 2005; ORTIZ, 2002; ZAMORA, 2001; RÊGO, 1999). No Brasil, encontram-se pesquisas detalhadas sobre produtos oriundos do extrativismo e seus benefícios e limitações sociais, ambientais e econômicas. Como exemplo, tem-se a castanha-do-brasil (Bertholletia excelssa H.B.K.), o açaí (Euterpe oleracea Mart) e o látex de seringueira (Hevea brasiliensis Muell). Porém muitos produtos e os benefícios ou limitações atrelados a eles ainda estão invisíveis aos olhos das estatísticas oficiais, mesmo que há décadas venha ocorrendo sua comercialização. Um desses produtos é a semente de cumaru (Dipteryx odorata (Aubl.) Willd.), que há quase um século é comercializada por extrativistas da Amazônia, a principal região produtora. Da semente do cumaru é extraída a cumarina, utilizada na indústria de perfumaria e cosméticos. Em 2005, foram comercializadas 110 toneladas de sementes, que gerou uma renda de $\mathrm{R} \$ 440$ mil (IGBE, 2006).

O cumaru é também conhecido popularmente como baru, champanhe, cumaru-de-folha-grande, ipê-cumaru, serrápia, fava tonka e tonka bean (SOUZA, 2001). A espécie pertence à família Papilionidae, que possui aproximadamente 500 gêneros e 10.000 espécies, amplamente distribuídas nas zonas tropicais e subtropicais, estendendo-se às regiões temperadas. Porém sua maior diversidade encontra-se nos trópicos americanos e africanos (RIBEIRO et al., 1999). O cumaru é uma árvore de grande porte, que pode atingir até $30 \mathrm{~m}$ de altura em mata primária. Na Amazônia brasileira, é encontrada desde o Acre até o Maranhão (LORENZI, 1998). O ritidoma é pardo-amarelado, escuro (RIBEIRO et al., 1999). As flores são aromáticas, dispostas em panículas longas, que exalam perfume forte e agradável (LORENZI; MATOS, 2002).

Os frutos são do tipo drupa, com endocarpo lenhoso e uma única semente aromática. A dispersão dos frutos ocorre intermitentemente ao longo do ano, sendo mais pronunciada entre os meses de novembro e março. A dispersão é epizoocórica, sendo consumidos ainda na copa das árvores por morcegos e aves, e no chão da floresta, após caírem pela força da gravidade, por mamíferos de médio porte (MAUÉS, 2006). O florescimento é assincrônico e ocorre em dois períodos do ano, no final das chuvas e no auge da estiagem, com numerosas flores de coloração rosa intenso a púrpura, que liberam uma fragrância bastante agradável e adocicada (MAUÉS; MCQUEEN; SANTOS, 1999). 
Devido à utilização da espécie no mercado nacional e internacional, este artigo busca analisar e compreender a cadeia produtiva da semente de cumaru no estado do Pará. As informações aqui contidas podem contribuir para a formulação de estratégias que favoreçam o extrativismo na região, pois elucida aspectos mercadológicos que ainda não haviam sido analisados.

\section{MATERIAL E MÉTODOS}

\section{Área de estudo}

A pesquisa foi realizada em 2006, tendo como referência a safra de 2005. A principal região de estudo foi a Mesorregião do Baixo Rio Amazonas, indicada pelo IBGE como a maior produtora do Pará. O estudo foi conduzido nos municípios de Alenquer, Monte Alegre, Santarém e Óbidos. Nessa região, foram entrevistados coletores, atravessadores e empresas atacadistas. O Baixo Amazonas é a quarta mesorregião mais populosa do estado do Pará. De acordo com a divisão administrativa do estado, é formada por 14 municípios. A mesorregião é caracterizada pela atividade agropecuária, pesqueira e extrativista. A agricultura familiar é a forma predominante de uso da terra, mas também são encontrados grandes latifúndios. A densidade populacional do território é de 2,47 habitantes $/ \mathrm{km}^{2}$, uma das mais baixas do estado do Pará (MINISTÉRIO DO DESENVOLVIMENTO AGRÁRIO, 2005).

Em Belém, foram entrevistados representantes de empresas atacadistas que adquirem o produto e enviam para outras regiões do país e/ou exterior. Além disso, foram entrevistados os feirantes e casas especializadas na venda de produtos naturais.

\section{Coleta de dados}

Os dados foram coletados junto ao Instituto Brasileiro de Geografia e Estatística (IBGE), disponibilizados pela Secretaria de Estado de Planejamento, Orçamento e Finanças (SEPOF) do Pará. Os dados sobre exportação foram obtidos no Sistema Aliceweb do Ministério da Indústria, Desenvolvimento e Comércio Exterior (MDIC). Após esse período, não há dados discriminados, pois os produtos exportados em quantidades inferiores a 100 toneladas são classificados como "Outros", o que impossibilita qualquer rastreamento de origem ou destino. Também foi realizado um levantamento bibliográfico a respeito do mercado do produto e trabalhos relacionado com a espécie.

O levantamento das informações a respeito dos diversos agentes da cadeia produtiva foi realizado através de entrevistas com eles na região do Baixo Amazonas e Belém (Tabela 1).

Tabela 1. Relação dos agentes entrevistados durante a pesquisa.

Table 1. Relation of interviewed agents during the research.

\begin{tabular}{lc}
\hline Agente & Número de entrevistados \\
\hline Extrativista & 20 (10 em Monte Alegre e 10 em Alenquer $)$ \\
Atravessador I (que se desloca até as comunidades) & 3 (Alenquer) \\
Atravessador II (fixo na cidade) & 3 (2 em Alenquer e 1 em Óbidos) \\
Empresas no interior & $7(4$ em Alenquer, 1 em Óbidos e 2 em Santarém) \\
Empresas em Belém & 3 \\
Feirantes em Belém & 7 \\
\hline
\end{tabular}

Durante as entrevistas, cada agente indicava o próximo a ser entrevistado. Assim, os diversos elos da cadeia foram se conectando, o que possibilitou o contato com aqueles que comercializam o produto. Essa metodologia é recomendada por Marshall (2006).

Junto aos extratores, as principais questões levantadas foram: há quanto tempo exploram a espécie; onde ocorre a coleta; quantidade coletada nos últimos cinco anos; valor da produção; principais limitações e oportunidades da espécie.

As questões levantadas junto aos atravessadores trataram das estratégias de compra, determinação dos preços, principais clientes e destinos do produto. Com os exportadores, foram levantadas informações sobre os destinos do produto, preços auferidos, quantidades transacionadas e origem do produto. Por fim, foram entrevistados todos os feirantes das cinco principais feiras de Belém e oito casas de produtos regionais. Foram identificados apenas quatro feirantes que comercializavam o produto e três casas especializadas na venda de produtos regionais. 
Com essas informações, foram gerados gráficos para análise do comportamento da produção, calculados a elasticidade do produto e os preços médios ao longo da cadeia, e caracterizados os agentes e perspectivas de mercado. Foi elaborado o fluxograma da cadeia produtiva e analisados os aspectos referentes aos fluxos físicos e financeiros. Para analisar os ganhos nos diferentes elos da cadeia de comercialização, foram usados os conceitos de margem e markup de comercialização (Tabela 2).

Para Mendes (1994), a margem bruta (Mb) de comercialização refere-se à diferença entre preços nos diferentes níveis do sistema de comercialização. A margem total (Mt) é a diferença entre o preço pago pelo consumidor e o preço recebido pelo produtor (Tabela 2). Esse instrumento é um importante componente na discussão sobre o tema da cadeia produtiva das amêndoas de cumaru. Com esse dado, é possível compreender o processo de reajuste do preço ao longo da cadeia e, principalmente, quem e em quanto o faz.

Tabela 2. Fórmulas utilizadas no cálculo da margem bruta $(\mathrm{Mb})$.

Table 2. Formulas used on the rude edge (RE) calculation.

\begin{tabular}{lcc}
\hline Margem & Valor absoluto & Valor relativo \\
\hline Total (Mt) & $\mathrm{Pv}-\mathrm{Pe}$ & {$[(\mathrm{Pv}-\mathrm{Pe}) / \mathrm{Pv}] 100$} \\
Empresa atacadista 2 (Ma2) & $\mathrm{Pa} 2-\mathrm{Pa} 1$ & {$[(\mathrm{~Pa} 2-\mathrm{Pa} 1) / \mathrm{Pv}] 100$} \\
Empresa atacadista 1 (Ma1) & $\mathrm{Pa} 1-\mathrm{Pa}$ & {$[(\mathrm{Pa} 1-\mathrm{Pa}) / \mathrm{Pv}] 100$} \\
Atravessador $(\mathrm{Ma})$ & $\mathrm{Pa}-\mathrm{Pv}$ & {$[(\mathrm{Pa}-\mathrm{Pv}) / \mathrm{Pv}] 100$} \\
Extrativista $(\mathrm{Mv})$ & $\mathrm{Pv}-(\mathrm{Pv}-\mathrm{Pe})$ & {$[[\mathrm{Pv}-(\mathrm{Pv}-\mathrm{Pe})] / \mathrm{Pv}\} 100$} \\
\hline
\end{tabular}

Fonte: Adaptado de Mendes (1994).

Em que: $\mathrm{Pv}=$ preço pago pelo consumidor final;

$\mathrm{Pa} 2$ = preço pago no nível das empresas atacadistas em Belém;

$\mathrm{Pa} 1=$ preço pago no nível das empresas atacadistas no interior;

$\mathrm{Pa}=$ preço no nível dos atravessadores;

$\mathrm{Pe}=$ preço recebido pelos extrativistas;

$\sum \mathrm{P}=$ somatória dos preços com exceção de $\mathrm{Pe}$.

O markup (Mk) é outra ferramenta que analisa as diferenças de ganhos em função dos reajustes de preços efetuados ao longo da cadeia por seus vários agentes. O Mk pode ser definido como a diferença entre o preço de venda e o preço de compra (ou de custo). Em termos absolutos, o Mk é igual à margem (Tabela 3). Em termos relativos, mostra o percentual de aumento entre os preços de venda e de compra, relativamente ao preço de compra, ou entre o preço de venda e o custo de produção, relativamente ao custo de produção, como mostrado a seguir (MENDES, 1994).

Tabela 3. Fórmulas utilizadas no cálculo do markup (Mk).

Table 3. Formulas used for the markup (MK) calculation.

\begin{tabular}{lcc}
\hline Markup & Valor absoluto & Valor relativo \\
\hline Total $(\mathrm{Mt})$ & $\mathrm{Pv}-\mathrm{Pe}$ & {$[(\mathrm{Pv}-\mathrm{Pe}) / \mathrm{Pe}] \times 100$} \\
Empresa atacadista 2 (Ma2) & $\mathrm{Pa} 2-\mathrm{Pa} 1$ & {$[(\mathrm{~Pa} 2-\mathrm{Pa} 1) / \mathrm{Pa} 1] \times 100$} \\
Empresa atacadista 1 (Ma1) & $\mathrm{Pa} 1-\mathrm{Pa}$ & {$[(\mathrm{Pa} 1-\mathrm{Pa}) / \mathrm{Pa}] \times 100$} \\
Atravessador $(\mathrm{Ma})$ & $\mathrm{Pa}-\mathrm{Pv}$ & {$[(\mathrm{Pa}-\mathrm{Pv}) / \mathrm{Pa}$} \\
Extrativista $(\mathrm{Mv})$ & $\mathrm{Pv}-(\mathrm{Pv}-\mathrm{Pe})$ & {$[[\mathrm{Pv}-(\mathrm{Pv}-\mathrm{Pe})] / \mathrm{Pv}\} 100$}
\end{tabular}

Fonte: Adaptado de Mendes (1994).

Para o cálculo dessas duas variáveis, foram utilizados os valores médios obtidos na pesquisa de campo.

\section{RESULTADOS E DISCUSSÃO}

No período de 1989 a 1996, o Brasil exportou aproximadamente 685,4 toneladas de sementes de cumaru, que geraram uma renda bruta de U\$2.882.298,00 (figuras 1 e 2). O preço do quilo girou em torno de U\$ 6,00. Quem mais importou foi Hong Kong, com 37\% do total. Em segundo lugar está a Alemanha, com $27 \%$ (Tabela 4). Os países europeus respondem por aproximadamente $48 \%$ das importações. 


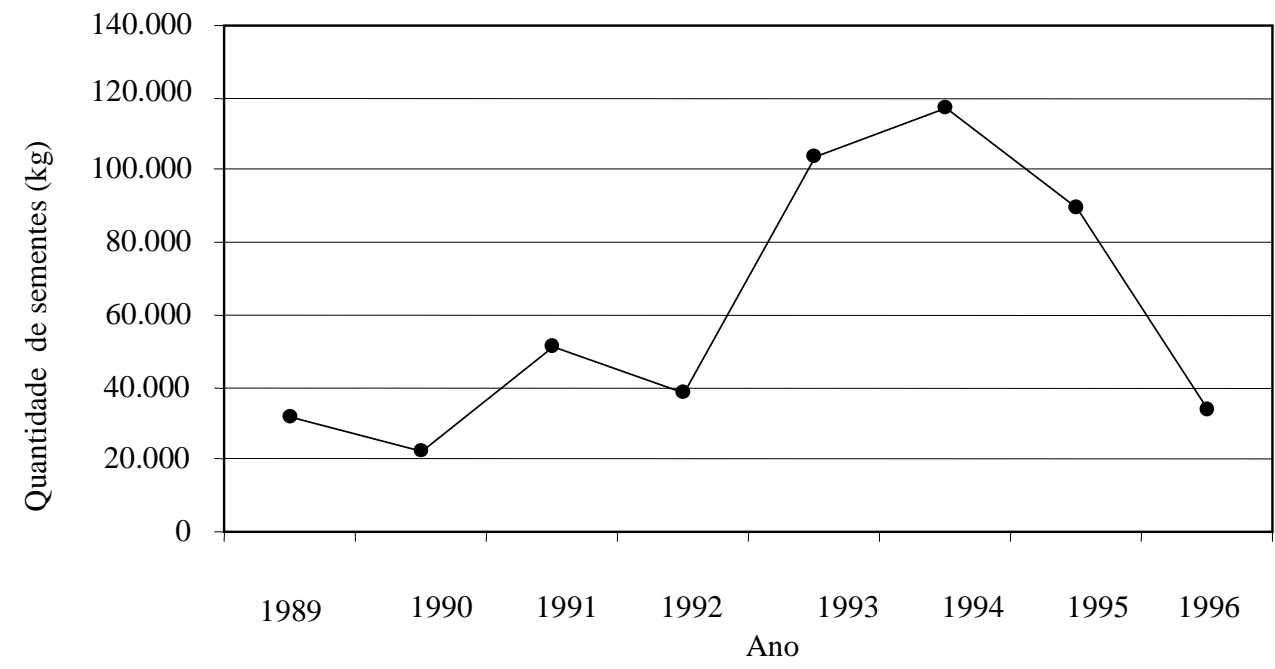

Fonte: IBGE.

Figura 1. Quantidade de sementes de cumaru exportada pelo Brasil no período de 1989 a 1996.

Figure 1. Quantity of cumaru seeds exported by Brazil from 1989 to 1996.

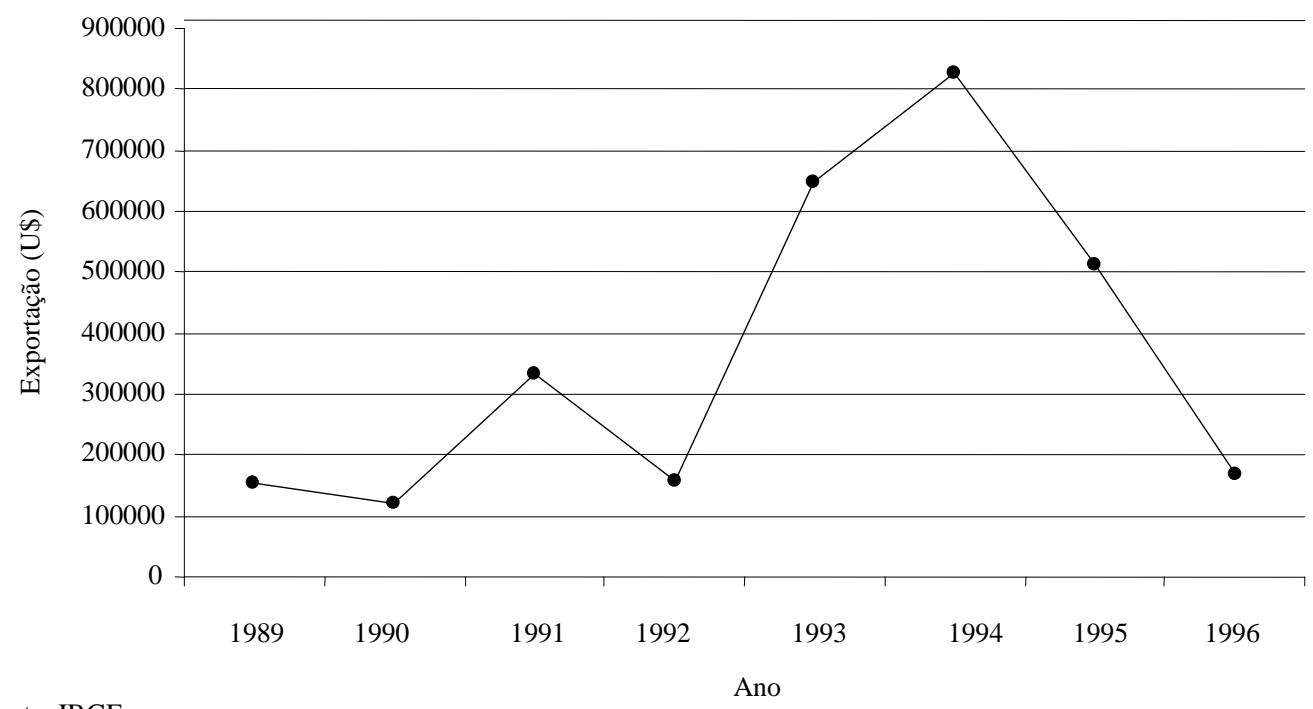

Fonte: IBGE.

Figura 2. Valor das exportações brasileiras de sementes de cumaru no período de 1989 a 1996.

Figure 2. Brazilian exported value of cumaru seeds from 1989 to 1996.

O pico de exportação ocorre em 1994. Isso acontece devido à implantação do Plano Real, que valorizou a moeda nacional. A queda nas exportações a partir de 1994 é atribuída à substituição da cumarina natural pela sintética (CLAI; SAMPAIO; CLEMENT, 2000).

De acordo com os dados do IBGE, o estado do Pará é responsável por praticamente toda a produção de sementes de cumaru. A principal região produtora é o Baixo Amazonas, respondendo por quase toda a produção do Brasil. O município de Alenquer é apontado como o maior produtor, com cerca de $59,5 \%$ da produção em 2005 , enquanto Óbidos responde por $24,3 \%$. Os demais municípios respondem por $16,2 \%$ (Tabelas 5 e 6). A pesquisa mostrou que esses dois municípios não produzem toda a quantidade registrada pelo IBGE. Eles agregam a produção de Monte Alegre, Santarém, Prainha e Oriximiná. O registro é obtido na localidade da emissão da nota fiscal, mascarando assim a verdadeira origem de parte da produção. 
Tabela 4. Principais países importadores de sementes de cumaru no período de 1989 a 1996.

Table 4. Main import countries of cumaru seeds from 1989 to 1996.

\begin{tabular}{|c|c|c|c|c|c|c|}
\hline \multirow{2}{*}{ País } & \multicolumn{2}{|c|}{ Média de 1989 a 1996} & \multicolumn{2}{|c|}{ Total de 1989 a 1996} & \multirow{2}{*}{ kg em U\$ } & \multirow{2}{*}{$\begin{array}{c}\text { Participação } \\
(\%)\end{array}$} \\
\hline & kg & U\$ & kg & U\$ & & \\
\hline Alemanha & $16.687,50$ & $86.112,38$ & $133.500,00$ & $688.899,00$ & 5,16 & 27,39 \\
\hline Bélgica & 500,00 & $3.000,00$ & 500,00 & $3.000,00$ & 6,00 & 0,10 \\
\hline China & $2.000,00$ & $12.710,00$ & $2.000,00$ & $12.710,00$ & 6,36 & 0,41 \\
\hline Estados Unidos & $4.268,40$ & $31.834,40$ & $21.342,00$ & $159.172,00$ & 7,46 & 4,38 \\
\hline França & $13.015,00$ & $51.990,71$ & $91.105,00$ & $363.935,00$ & 3,99 & 18,69 \\
\hline Hong Kong* & $22.575,00$ & $168.207,88$ & $180.600,00$ & $1.345 .663,00$ & 7,45 & 37,05 \\
\hline Índia & $8.500,00$ & $40.700,00$ & $8.500,00$ & $40.700,00$ & 4,79 & 1,74 \\
\hline Itália & $3.750,00$ & $23.254,00$ & $7.500,00$ & $46.508,00$ & 6,20 & 1,54 \\
\hline Japão & 866,67 & $9.234,33$ & $2.600,00$ & $27.703,00$ & 10,66 & 0,53 \\
\hline Reino Unido & $9.120,00$ & $53.260,00$ & $36.480,00$ & $213.040,00$ & 5,84 & 7,48 \\
\hline Suíça & 837,50 & $4.365,00$ & $3.350,00$ & $17.460,00$ & 5,21 & 0,69 \\
\hline
\end{tabular}

Fonte: Aliceweb 2006.

*Valor destacado da China, pois o volume é muito representativo.

Tabela 5. Quantidade em toneladas de amêndoas de cumaru produzidas nos municípios do estado do Pará.

Table 5. Cumaru almonds quantity produced in the municipalities of the State of Pará.

\begin{tabular}{lcccccccccc}
\hline Municípios & $\mathbf{1 9 9 7}$ & $\mathbf{1 9 9 8}$ & $\mathbf{1 9 9 9}$ & $\mathbf{2 0 0 0}$ & $\mathbf{2 0 0 1}$ & $\mathbf{2 0 0 2}$ & $\mathbf{2 0 0 3}$ & $\mathbf{2 0 0 4}$ & $\mathbf{2 0 0 5}$ & Total \\
\hline Alenquer & 17 & 8 & 10 & 5 & 6 & 6 & 75 & 70 & 60 & 257 \\
Altamira & 2 & 1 & 2 & 2 & 2 & 1 & 1 & 1 & 1 & 13 \\
Cametá & - & - & - & - & 1 & 1 & 1 & 1 & 1 & 5 \\
Curuá & - & - & - & - & - & - & 2 & 1 & 5 & 8 \\
Juruti & - & - & - & 0 & 1 & 0 & 0 & 0 & 1 & 2 \\
Óbidos & 20 & 1 & 0 & 1 & 20 & 8 & 11 & 10 & 34 & 105 \\
Oriximiná & 0 & - & 1 & - & 5 & 1 & 5 & 3 & 6 & 21 \\
Santarém & 4 & 2 & 3 & 3 & 3 & 1 & 2 & 2 & 2 & 22 \\
\hline Total & 43 & 12 & 16 & 11 & 38 & 18 & 97 & 88 & 110 & 861 \\
\hline
\end{tabular}

Fonte: IBGE, 2006.

A participação da semente de cumaru na economia dos municípios é incipiente, pois essa atividade extrativista não gera grandes contribuições ao Produto Interno Bruto (Tabela 7). Porém, para os extrativistas, essa participação representa um incremento de renda anual que colabora na manutenção das famílias. Além disso, a coleta de cumaru representa um controle maior do desmatamento, pois quem utiliza o produto normalmente preserva as matrizes (ALEXIADES; SHANLEY, 2004).

Tabela 6. Valores em mil reais da produção de amêndoas de cumaru nos municípios do estado do Pará.

Table 6. Values in thousand Reais of the production of cumaru almonds on the municipalities of Pará.

\begin{tabular}{lcccccccccc}
\hline Municípios & $\mathbf{1 9 9 7}$ & $\mathbf{1 9 9 8}$ & $\mathbf{1 9 9 9}$ & $\mathbf{2 0 0 0}$ & $\mathbf{2 0 0 1}$ & $\mathbf{2 0 0 2}$ & $\mathbf{2 0 0 3}$ & $\mathbf{2 0 0 4}$ & $\mathbf{2 0 0 5}$ & Total \\
\hline Alenquer & 17 & 10 & 14 & 8 & 11 & 11 & 263 & 245 & 240 & 819 \\
Altamira & 2 & 1 & 2 & 2 & 2 & 1 & 1 & 2 & 1 & 14 \\
Cametá & - & - & - & - & 1 & 1 & 1 & 1 & 1 & 5 \\
Curuá & - & - & - & - & - & - & 7 & 5 & 19 & 31 \\
Juruti & - & - & - & - & 1 & 1 & 2 & 2 & 2 & 8 \\
Óbidos & 14 & - & - & - & 36 & 24 & 34 & 37 & 145 & 290 \\
Oriximiná & - & - & - & - & 9 & 5 & 24 & 17 & 25 & 80 \\
Santarém & 4 & 3 & 5 & 4 & 5 & 3 & 4 & 5 & 7 & 40 \\
\hline Total & 37 & 14 & 21 & 14 & 65 & 46 & 336 & 314 & 440 & 2.574 \\
\hline
\end{tabular}

Fonte: IBGE 2006. 
Tabela 7. Participação do extrativismo de amêndoas de cumaru no PIB dos municípios da Mesorregião do Baixo Amazonas (dados parciais referentes a 2006).

Table 7. Participation of extraction of cumaru almonds on Internal Rude Product (IRP) of municipalities in the middle region of Baixo Amazonas (partial data referring the 2006).

\begin{tabular}{lccc}
\hline Municípios & $\begin{array}{c}\text { Valor da produção de cumaru em } \\
\text { mil reais }\end{array}$ & PIB em R\$ & Participação \% \\
\hline Alenquer & $594.000,00$ & $111.553 .000,00$ & 0,532 \\
Altamira & $13.000,00$ & $368.845 .000,00$ & 0,004 \\
Cametá & $4.000,00$ & $202.269 .000,00$ & 0,002 \\
Curuá & $12.000,00$ & $27.293 .000,00$ & 0,044 \\
Juruti & $6.000,00$ & $69.973 .000,00$ & 0,009 \\
Óbidos & $145.000,00$ & $138.489 .000,00$ & 0,105 \\
Oriximiná & $55.000,00$ & $7.776 .845 .000,00$ & 0,001 \\
Santarém & $35.000,00$ & $1.266 .535 .000,00$ & 0,003 \\
\hline Média & $108.000,00$ & $1.245 .225 .250,00$ & 0,09 \\
\hline Fonte: IBGE 2006. & & &
\end{tabular}

\section{Margem Bruta (Mb) e Markup (Mk)}

A análise da $\mathrm{Mb}$ mostrou que os produtores e os atravessadores ficam com a menor margem de comercialização ao longo da cadeia. As empresas atacadistas são os agentes que mais elevam o preço do produto. O Mk reafirma essa tendência, visto que os incrementos para as empresas atacadistas foram superiores a $150 \%$ do valor pago ao coletor (Tabela 8). Esse aumento seria justificado pelos impostos e custos de transporte, que são mais elevados a partir desse ponto da cadeia.

Tabela 8. Margem Bruta (Mb) e Markup (Mk), por agente da cadeia da comercialização de amêndoas de cumaru no estado do Pará.

Table 8. The Gross Edge (Mb) and Markup (Mk) by agent of the trade chain of cumaru almonds in the State of Pará.

\begin{tabular}{lcccc}
\hline Categoria & Preços médios R\$ & Mb em R\$ & Mb \% & Mk \% \\
\hline Coletor & 3,00 & 3,00 & 20,00 & \\
Atravessadores & 3,75 & 2,25 & 15,00 & 75 \\
Empresa atacadista no interior do estado & 6,00 & 5,00 & 33,33 & 166,7 \\
Empresa atacadista em Belém & 11,00 & 7,00 & 46,67 & 233,3 \\
Consumidor final* & 18,00 & & & \\
\hline Média & 8,35 & & & \\
\hline Total & & 17,25 & 115,00 & 500 \\
\hline
\end{tabular}

*São consideradas as empresas de outros estados ou países que transformam as sementes em extratos e/ou outro produto.

\section{Canal de comercialização}

Todo produto segue um caminho desde sua produção ou coleta até o consumidor final. Esse caminho é definido como canal de comercialização. É nesse canal que se podem identificar os diferentes atores, variações de preço e transformações do produto. No caso da amêndoa do cumaru, que é um produto oriundo do extrativismo, o canal de comercialização nem sempre é linear, envolvendo diversos agentes que não se sobrepõem em suas atividades. O canal de comercialização do cumaru apresenta a seguinte estrutura (Figura 3).

\section{Os coletores de cumaru e seu contexto socioeconômico}

O aproveitamento da semente de cumaru é realizado por famílias de agricultores que se dedicam principalmente à pecuária na área de pesquisa. A safra ocorre, normalmente, no período de setembro a novembro, época que coincide com a entressafra da maioria dos produtos agrícolas. A coleta é realizada nas áreas de mata primária ou secundária das propriedades, e também nos vizinhos, ou onde ainda encontram-se cumaruzais. Os lotes variam de 25 a 100 ha, com uma média de 63 ha. Já as áreas de mata em cada propriedade variam de 2 a 82 ha, com média girando em torno de 33 ha. 
A coleta é realizada por todos os membros da família, sendo que os homens são responsáveis por catar os frutos e depositá-los embaixo das árvores. Cada fruto possui apenas uma semente, que é liberada quando o fruto é golpeado com um machadinho ou facão. Essa etapa da "quebra" do cumaru é feita principalmente por mulheres e crianças. Algumas famílias se dedicam integralmente à coleta na época da safra. Outras apenas algumas horas por dia, principalmente no final da tarde, quando as demais atividades já cessaram.

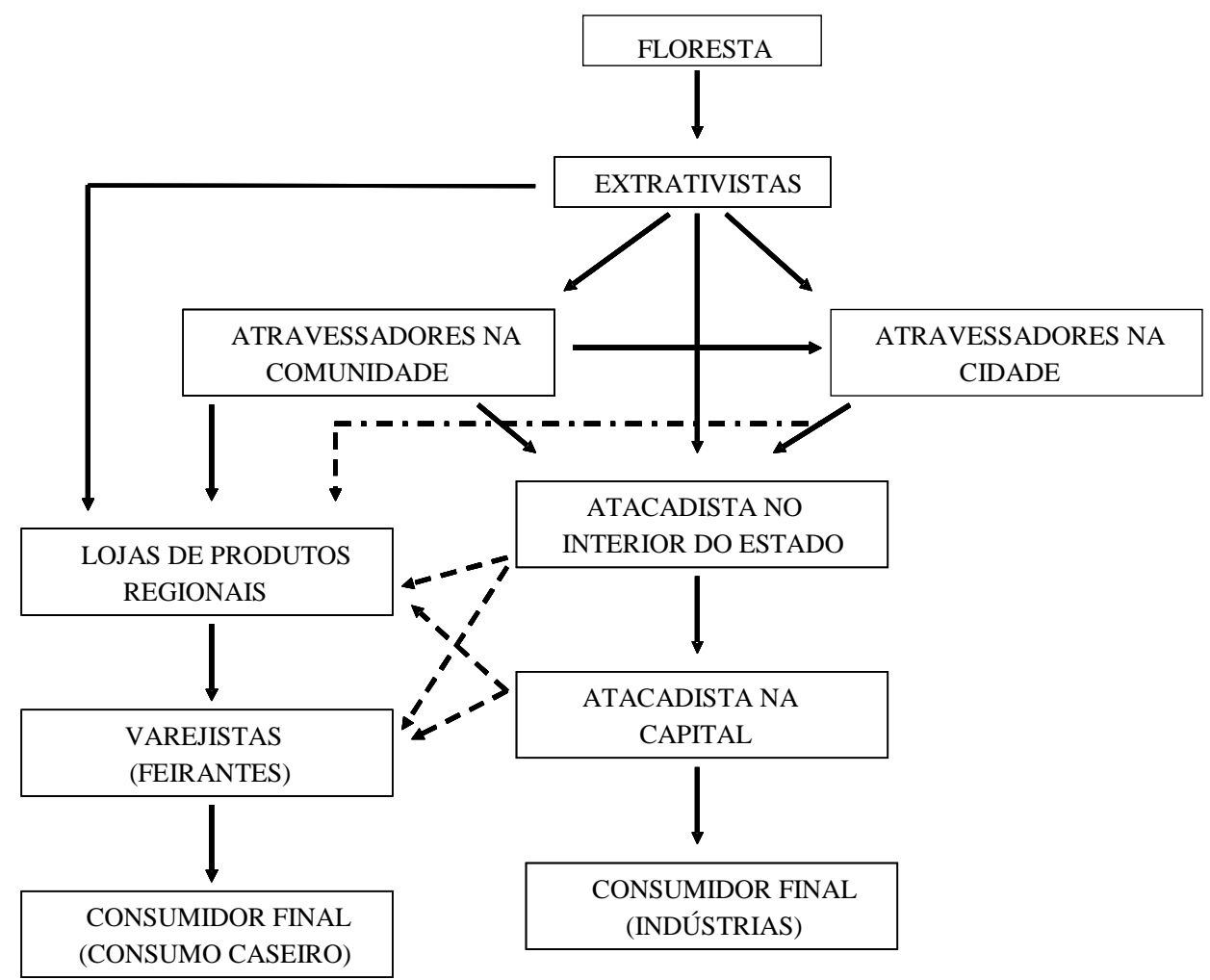

Figura 3. Esquema do fluxo da amêndoa de cumaru no estado do Pará.

Figure 3. Diagram of the flow of cumaru almonds in the state of Pará.

Após a quebra, as sementes são colocadas para secar. Essa etapa leva de dois a três dias e pode ser dispensada caso haja compradores já interessados em levar o produto ainda "verde".

De acordo com os coletores, a produção de sementes não é regular. Se em um ano há uma boa produção, no ano seguinte isso não ocorre. Além disso, a cada quatro anos há uma grande produção de frutos. Durante as safras menores, as mulheres e as crianças respondem por quase $80 \%$ da coleta de sementes. Porém, quando o preço ou a produção aumenta, os homens passam a controlar a atividade.

Um terço dos entrevistados trabalha com cumaru desde a infância (há mais de 30 anos). Outro terço está na atividade há aproximadamente 20 anos, e o restante começou a trabalhar com o produto na última década. É importante salientar que o extrativismo de cumaru, ou de qualquer outro produto, não foi considerado, em nenhuma das entrevistas, como a atividade mais importante da família. A pecuária e a agricultura ocuparam a primeira posição em Monte Alegre e Alenquer, respectivamente. Metade dos entrevistados recebe algum tipo de benefício (bolsa escola ou aposentadoria). Para os beneficiários, esses auxílios representam a segunda forma de renda mais importante, visto que têm uma regularidade mensal.

O comércio de cumaru ocorre tanto dentro das comunidades quanto em Alenquer, Santarém e Óbidos. Porém há uma diferença no preço, de acordo com a localidade. Dentro do perímetro de Alenquer e Santarém, o preço varia em torno de $\mathrm{R} \$ 0,50$ por quilo. Nas comunidades de Monte Alegre, a variação é de aproximadamente $\mathrm{R} \$ 1,00$ a menos que nos demais municípios, pois só os atravessadores de Alenquer vão buscar as sementes, já que na cidade de Monte Alegre não há compradores interessados no produto. 
A semente é vendida de duas formas: seca (amêndoa) ou verde. A pesquisa de campo mostrou que o preço da amêndoa varia de $\mathrm{R} \$ 2,50 / \mathrm{kg}$ a $\mathrm{R} \$ 12,00 / \mathrm{kg}$. Este valor só foi alcançado em 2004. O preço pago ao coletor pela semente verde é, normalmente, metade daquele pago pela semente seca e varia de $\mathrm{R} \$ 2,40$ a $\mathrm{R} \$ 6,00 / \mathrm{kg}$. A cada safra, o preço inicial gira em torno de $\mathrm{R} \$ 2,00$ a $\mathrm{R} \$ 4,00$ e sobe ao longo dos meses, até estabilizar, no final de outubro. O preço médio em 2005 foi de $\mathrm{R} \$ 3,00 / \mathrm{kg}$.

Cada família coleta em torno de $80 \mathrm{~kg}$ de sementes verdes, que equivalem a $40 \mathrm{~kg}$ de amêndoas. Se considerarmos a produção de 110 toneladas em 2005 (IBGE, 2006), teremos que aproximadamente 2.700 famílias estiveram envolvidas com o extrativismo de sementes de cumaru na região.

Não há organização das comunidades em torno da produção de amêndoas de cumaru. Cada família vende seu produto individualmente, tendo uma visão dos outros coletores como concorrentes e não como parceiros que podem fortalecer as relações com os compradores.

O principal problema identificado pelos extrativistas é o preço baixo na maioria dos anos. Além disso, foi apontada a falta de garantia para a compra. Muitas vezes, os frutos são coletados, mas não são quebrados, pois os compradores interrompem sua ida à comunidade, sem aviso prévio. Outro problema é a perda de produto na hora da pesagem. Os atravessadores sempre utilizam unidades de medida que lesam os extrativistas. Na região, é usado um recipiente de soda cáustica para medir o peso das amêndoas. Para os atravessadores, 3 latas equivalem a 1 quilo. Porém, segundo os coletores, bastam 1,5 a 2 latas para 1 quilo de amêndoas.

\section{Os atravessadores}

Dentro da cadeia produtiva de sementes de cumaru, existem dois tipos de atravessadores: 1) os que se deslocam até as comunidades para comprar cumaru; e 2) os que se estabelecem nos centros urbanos, principalmente Alenquer e Óbidos, além de comprarem as sementes dos produtores que vêm até a cidade, ou de outros atravessadores que chegam das comunidades rurais.

O primeiro grupo é formado por aproximadamente 15 atravessadores em Alenquer e $12 \mathrm{em}$ Óbidos. Estes se ocupam, durante o ano, com trabalhos temporários e também com a compra de castanhado-brasil, que é o principal produto florestal não-madeireiro (PFNM) comercializado na região. Como as safras desses dois produtos não coincidem, primeiramente é realizada a compra do cumaru e depois da castanha. O lucro gerado pela venda do cumaru é normalmente utilizado como capital de giro para a castanha. Não foi encontrado nenhum atravessador que comprasse somente cumaru, o que denota certa dependência da cadeia do cumaru à cadeia da castanha. Normalmente, as empresas exportadoras financiam a compra do cumaru. Assim, cada atravessador já tem uma ou mais empresas com a qual se compromete já no início da safra. Porém esse sistema não tem garantia total. Frequentemente, os atravessadores quebram os acordos quando outras empresas oferecem melhor preço ou pagamento imediato.

Os atravessadores se deslocam de moto pelos ramais e anunciam o período que estarão comprando sementes. Em cada viagem são trazidos no mínimo $50 \mathrm{~kg}$ de sementes. Normalmente, é preferível a semente seca, por não necessitar de beneficiamento para ser comercializada. Porém, eventualmente, os atravessadores adquirem e secam as sementes verdes para conservar e/ou agregar mais valor. A quantidade de sementes adquirida anualmente por esses atravessadores é difícil de ser mensurada, pois depende de pedidos de agentes mais avançados na cadeia. $\mathrm{O}$ relato do maior volume negociado por um único atravessador foi de 20 toneladas, em 2005.

O preço pago ao produtor depende da distância percorrida, da quantidade adquirida e da frequência com que o coletor dispõe do produto. Aqueles que dispõem do produto com maior regularidade podem barganhar um preço melhor (até $\mathrm{R} \$ 0,50$ a mais por quilo). A diferença entre o preço pago ao extrativista e o recebido pelos atravessadores é aproximadamente $\mathrm{R} \$ 0,75$. A mobilização para aquisição do produto se inicia até 2 meses antes da safra, pois é necessário visitar os extrativistas e estabelecer uma rede de relações eficientes para garantir produção.

Os atravessadores que se estabelecem na zona urbana recebem a produção de outros atravessadores oriundos das comunidades ou de coletores que vêm à cidade para vender o cumaru. Esses compradores instalam o ponto de compra em suas próprias casas ou em pequenos estabelecimentos espalhados pela cidade, que durante a safra chegam às dezenas.

Esse segundo grupo privilegia a compra direta de outros atravessadores, pois estes normalmente chegam com volumes maiores. Em média pagam $\mathrm{R} \$ 0,75$ a mais pelo produto de outros atravessadores. 
O papel dos atravessadores no extrativismo vem sendo historicamente questionado. No caso do cumaru, pelo menos o primeiro grupo aqui apresentado é essencial para o funcionamento da cadeia, visto que os agentes mais avançados não se propõem a buscar o produto nas comunidades, devido aos custos de transação e tempo despendido.

$\mathrm{Na}$ visão dos atravessadores, o principal problema é a falta de informação sobre a demanda externa e os preços praticados, pois necessitam de tempo para estabelecer sua rede de compra e venda.

\section{Empresas atacadistas no interior do estado}

Foram identificadas 7 empresas que compram cumaru, sendo que 4 estão localizadas em Alenquer, uma em Santarém e duas em Óbidos. Vale ressaltar que esses estabelecimentos possuem pouca infraestrutura para a realização das atividades a que se propõem. Frequentemente, dispõem de galpões já desgastados pelas décadas de uso. Essas empresas compram tanto dos extrativistas quanto dos atravessadores. Diferentemente dos estabelecimentos temporários, que surgem com a oportunidade de compra e venda do cumaru na safra, essas empresas já estão estabelecidas há mais de 10 anos em suas cidades. Com exceção de uma empresa em Alenquer, que tem o cumaru como único produto florestal de seu escopo, todas as demais possuem uma maior variedade de PFNM, sendo o principal produto a castanha-do-brasil. É justamente a estrutura de armazenamento e comercialização da castanha que permite a viabilidade de comercialização da amêndoa de cumaru. A quantidade de produto transacionada não justificaria o investimento em armazéns e galpões de secagem.

A quantidade de amêndoas adquirida por essas empresas pode chegar a 60 toneladas. O preço de venda varia de 6,00 a $\mathrm{R} \$ 18,00 / \mathrm{kg}$. Essas empresas encaminham seu produto principalmente para Belém, São Paulo e Manaus. É frequente o comércio de pequenas quantidades $(0,5$ a 1t) com Macapá e outras cidades do Pará, como Mocajuba, Castanhal e Santa Izabel. Em seguida, as amêndoas seguem para Belém, onde abastecem as casas de plantas medicinais e ervanários.

É importante salientar que essas empresas são legalizadas, o que as habilita a enviar o produto para outros estados e municípios. Esse papel não é exercido pelos primeiros agentes da cadeia.

A grande dificuldade apontada por esse elo é a falta de documentação de origem do produto que, muitas vezes, é exigido pelos órgãos de fiscalização e pelas empresas de grande porte que precisam exportar para outros países. Frequentemente, deixam de atender pedidos por falta das autorizações necessárias.

\section{Empresas atacadistas em Belém}

Em Belém, encontram-se três empresas que compram e vendem sementes de cumaru. Duas delas são especializadas na exportação de produtos agrícolas e florestais, e a última trabalha apenas com cumaru. As duas primeiras respondem por cerca de 80 a $90 \%$ de toda a comercialização do produto no Pará. Para garantir seu abastecimento, há um sistema eficiente que envolve os atravessadores e empresas locais. O preço pago pelo produto varia de 8,00 a $\mathrm{R} \$ 14,00 / \mathrm{kg}$, dependendo da localidade e da quantidade transacionada, com média de $\mathrm{R} \$ 11,00$. O preço de venda pode chegar até $\mathrm{R} \$ 24,00 / \mathrm{kg}$ da semente peletizada. O produto é enviado de navio principalmente para Japão, França, Alemanha e China. Já em São Paulo, foram identificadas 2 empresas que repassam o produto para o exterior ou para indústrias brasileiras de cosméticos e perfumaria.

Essas empresas têm, aparentemente, maiores influências na determinação do preço do produto, visto que a concorrência faz com que elas ofereçam maiores vantagens para seus fornecedores. Para essas empresas, a principal limitação é a desorganização da produção, o que normalmente dificulta a aquisição do produto, elevando seus custos.

\section{Comércio nas feiras e ervanários}

A comercialização de PFNM nas feiras é uma atividade secular na região Norte do país. Em Belém, esses pontos de venda disponibilizam os mais variados produtos para alimentação, saúde, práticas religiosas e peças artesanais. A semente de cumaru é encontrada nas bancas mistas, que vendem ervas medicinais e produtos religiosos. Em 2005, foram comercializados aproximadamente $570 \mathrm{~kg}$ de sementes secas, gerando uma renda de $\mathrm{R} \$ 11.700,00$. Cerca de $83 \%$ desse total foi agenciado pelas casas de ervas e $17 \%$ pela feira do Ver-o-Peso. Os fornecedores desse elo estão principalmente na Ilha do Marajó e em municípios próximos a Belém, visto que as quantidades compradas são pequenas. O preço pago pelo produto varia de 8,00 a $\mathrm{R} \$ 50,00 / \mathrm{kg}$, com média de $\mathrm{R} \$ 19,70$. O preço de venda varia de 12,00 a $\mathrm{R} \$ 60,00$, com média igual a 
$\mathrm{R} \$ 25,83$. Esses valores mais altos são alcançados por feirantes que compram matéria-prima de lojas de plantas regionais e revendem em embalagens contendo 4 a 5 sementes.

\section{CONCLUSÕES}

- A cadeia produtiva de amêndoas de cumaru apresenta uma estrutura relativamente simples, na qual cinco grupos de agentes desempenham papéis bem definidos.

- Os principais problemas identificados foram a falta de informação ao longo da cadeia, os baixos preços pagos aos extrativistas, a perda de produto na pesagem (quando os produtores vendem aos atravessadores), a falta de documentação de origem do produto e irregularidade no fornecimento. Por último, foi detectada a desorganização da produção, que provoca perdas ao produtor na hora da negociação com os compradores e promove uma instabilidade da oferta, fazendo com que as empresas adotem estratégias severas. Um exemplo é a redução do valor pago aos extrativistas, para garantir um estoque maior, como prevenção para o ano seguinte, caso não seja possível ter acesso à matéria-prima. Essa baixa no preço, por sua vez, tem como efeito colateral um maior desestímulo dos extrativistas.

- A cadeia do cumaru está intimamente ligada à cadeia da castanha-do-brasil. Ambas dividem a atenção de extrativistas, atravessadores e atacadistas. Toda a cadeia é "aquecida" com a demanda internacional. Mesmo que esse mercado tenha se mostrado ao mundo com uma aparência de justo, essa justiça ainda não é perceptível nas bases produtivas. Os extrativistas são mal remunerados pela atividade que exercem e ainda arcam com os passivos ambientais da atividade.

- A legislação brasileira também se mostra inadequada para atender a necessidade de pequenos produtores que privilegiam a utilização de produtos florestais não-madeireiros. Eles não recebem orientação dos órgãos de assistência técnica para conduzir a exploração, ao contrário de atividades como pecuária e agricultura, que recebem na região atenção especial desses órgãos e agências de financiamento, mesmo que sejam realizadas, muitas vezes, sem respeitar critérios técnicos ou econômicos.

- O extrativismo de cumaru ou de outras espécies florestais pode responder a demandas atuais de conservação, pois quem utiliza esses recursos normalmente evita a derrubada das árvores.

\section{REFERÊNCIAS}

ALEXIADES, M. N.; SHANLEY, P. Produtos forestales, medios de subsistência e conservacion. Indonésia: Center International Forestry Reseach, 2004.

AMIN, M. M. O extrativismo como fator de empobrecimento da economia do estado do Pará. In: XIMENES, T. (Org.). Perspectivas do desenvolvimento sustentável; uma contribuição para a Amazônia. Belém: UFPA/NAEA; UNAMAZ, 1997. p. 177-209.

BRASIL. Ministério do Desenvolvimento Agrário. Estudo da dinamização da economia do território do Baixo Amazonas. Brasília, DF, 2005.

HOMMA, A. F. O. Viabilidade econômica da extração de produtos florestais não madeiráveis. Belém: EMBRAPA, 2004.

IBGE - INSTITUO BRASILEIRO DE GEOGRAFIA E ESTATÍTICA. Produção da extração vegetal e da silvicultura. 2006.

MARSHALL, E.; NEWTON, A. C.; SCHRECKENBERG, K. Commercialization of non-timber forest products: first steps in analyzing the factors influencing success. International Forestry Review, Oxford, v. 5, n. 2. p. 128-137, 2003.

MARSHALL, E.; RUSHTON, J.; SCHRECKENBERG, K. Métodos de investigación de la comercialización de productos forestales no maderables. 2006. Disponível em: <http://quin.unepwcmc.org/forest/ntfp/outputs.cfm>. Acesso em: 7/5/2009. 
MAUÉS, M. M. Estratégias reprodutivas de espécies arbóreas e sua importância para o manejo e conservação florestal: Floresta Nacional do Tapajós (Belterra-PA). 206 p. Tese (Doutorado em Ecologia) - Universidade de Brasília. Instituto de Ciências Biológicas, Brasília, DF, 2006.

MAUÉS, M. M.; MCQUEEN, D.; SANTOS, L. F. Biologia da polinização do cumaru (Dipteryx odorata, Leg. Pap.), essência florestal nativa da Amazônia. In: SIMPÓSIO SILVICULTURA NA AMAZÔNIA ORIENTAL: contribuições do Projeto EMBRAPA/DFID (1999, Belém, PA). Resumos expandidos... Belém: Embrapa-CPATU/DFID, 1999. p. 116-120. (Documentos, v. 123).

MENDES, J. T. Comercialização agrícola. Curitiba: UFPR, 1994. 102 p.

NOGUEIRA, A. S.; SANTOS, A. J. dos; BITTENCOURT, A. M.; BOLZON, D. R.; PAULA, F. da S. de. Aspectos produtivos e econômicos da cadeia produtiva do cipó-preto no litoral paranaense. Floresta, Curitiba, v. 36, n. 3, p. 343-348, 2006.

RÊGO, J. F. do. Amazônia: do extrativismo ao neoextrativismo. Ciência Hoje, Rio de Janeiro. v. 25. n. 147, p. 62-65, 1999.

RIBEIRO, J. E. L. da S.; HOPKINS, M. J. G.; VICENTINI, A.; SOTHERS, C. A.; COSTA, M. A. da S.; BRITO, J. M. de; SOUZA, M. A. D. de; MARTINS, L. H. P.; LOHMANN, L. G.; ASSUNÇÃO, P. A. C. L.; PEREIRA, E. da C.; SILVA, C. F. da; MESQUITA, M. R.; PROCÓPIO, L. C. Flora da reserva Ducke: guia de identificação das plantas vasculares de terra-firme na Amazônia Central. Manaus. Instituto Nacional de Pesquisas da Amazônia, 1999.

RICKER, M.; DALY, D. Botânica econômica en los bosques tropicais: princípios e métodos para su estúdio y aprovechamiento. México: Editorial Diana, 1998.

ORTIZ, E. G. Brasil nuts (Bertholletia excelsa). In.: GUILLEN, Abraham; LAIRD, Sarah A., SHANLEY, Patricia; PIERCE, Alan R. (Eds.). Tapping the green market: certification adn management of non-timber forest products. London: Earhthscan, 2002. p. 61- 74.

SHNALEY, P.; MEDINA, G. (Eds.) Frutíferas e plantas úteis na vida amazônica. Belém: Centro Internacional para Pesquisa Florestal, 2005. 456 p.

SHANLEY, P.; PIERC, A.; LAIRD, S. Além da madeira: a certificação de produtos florestais nãomadeireiros. Belém: Centro Internacional para Pesquisa Florestal, 2006. 155 p.

SANTOS, A. J. dos; HILDEBRAND, E.; PACHECO, C. H. P.; PIRES, P. de T. de L.; ROCHADELLI, R. Produtos não madeireiros: conceituação, classificação, valoração e mercados. Floresta, Curitiba, v. 2, n. 33, p 215-224, 2003.

SOUZA, M. H.; MAGLIANO, M. M.; CAMARGOS, J. A. A.; SOUZA, M. R. de Madeiras tropicais brasileiras. 2 ed. Brasília: IBAMA, 2002.

ZAMORA, M. Analise de la informacion sobre produtos florestales no madereros em América Latina. San Tiago: FAO, 2001. 88 p. 